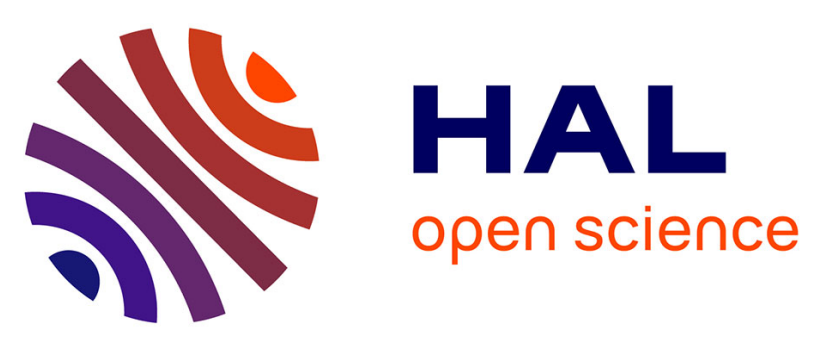

\title{
Evaluation of the Xpert MRSA assay for rapid detection of methicillin-resistant from nares swabs of geriatric hospitalized patients and failure to detect a specific SCC type IV variant
}

C. Laurent, P. Bogaerts, D. Schoevaerdts, O. Denis, A. Deplano, C. Swine, M. J. Struelens, Y. Glupczynski

\section{To cite this version:}

C. Laurent, P. Bogaerts, D. Schoevaerdts, O. Denis, A. Deplano, et al.. Evaluation of the Xpert MRSA assay for rapid detection of methicillin-resistant from nares swabs of geriatric hospitalized patients and failure to detect a specific SCC type IV variant. European Journal of Clinical Microbiology and Infectious Diseases, 2010, 29 (8), pp.995-1002. 10.1007/s10096-010-0958-3 . hal-00596688

\section{HAL Id: hal-00596688 https://hal.science/hal-00596688}

Submitted on 29 May 2011

HAL is a multi-disciplinary open access archive for the deposit and dissemination of scientific research documents, whether they are published or not. The documents may come from teaching and research institutions in France or abroad, or from public or private research centers.
L'archive ouverte pluridisciplinaire HAL, est destinée au dépôt et à la diffusion de documents scientifiques de niveau recherche, publiés ou non, émanant des établissements d'enseignement et de recherche français ou étrangers, des laboratoires publics ou privés. 


\title{
Evaluation of the Xpert MRSA assay for rapid detection of methicillin-resistant Staphylococcus aureus from nares swabs of geriatric hospitalized patients and failure to detect a specific SCCmec type IV variant
}

\author{
C. Laurent $\cdot$ P. Bogaerts $\cdot$ D. Schoevaerdts $\cdot$ O. Denis • \\ A. Deplano • C. Swine $\cdot$ M. J. Struelens $・$ Y. Glupczynski
}

Received: 2 January 2010 / Accepted: 6 May 2010/Published online: 29 May 2010

(C) Springer-Verlag 2010

\begin{abstract}
Rapid and reliable detection of methicillin-resistant Staphylococcus aureus (MRSA) carriers is crucial for control of MRSA nosocomial transmission. We aimed to evaluate the performance of the GeneXpert real-time PCR system using the Xpert MRSA assay on a collection of 40 representative Belgian MRSA strains and for MRSA screening of geriatric inpatients. Double nasal swabs were used: the first swab for the Xpert MRSA assay and the second for culture onto chromogenic selective medium and enrichment broth. All but 1 of the 40 collection strains were recognized as MRSA by the Xpert MRSA assay. Nares swabs were prospectively collected from 246 inpatients including 25 nasal MRSA carriers.
\end{abstract}

C. Laurent $\cdot$ P. Bogaerts $\cdot$ Y. Glupczynski $(\square)$

Department of Clinical Microbiology, Laboratoire de

Microbiologie, Cliniques Universitaires UCL Mont-Godinne,

1 Avenue G. Thérasse,

5530 Yvoir, Belgium

e-mail: Youri.Glupczynski@skynet.be

D. Schoevaerdts $\cdot$ C. Swine

Geriatric Unit, Department of Internal Medicine,

Cliniques Universitaires de Mont-Godinne-UCL,

1 Avenue G. Therasse,

5530 Yvoir, Belgium

O. Denis $\cdot$ A. Deplano $\cdot$ M. J. Struelens

Department of Clinical Microbiology and National MRSA

Reference Laboratory, Hôpital Erasme-ULB,

808 route de Lennik,

1070 Bruxelles, Belgium

Present Address:

M. J. Struelens

Antimicrobial Resistance and Healthcare-Associated Infections

Programme, Scientific Advice Unit,

European Centre for Disease Prevention and Control,

Stockholm, Sweden
Compared with enriched cultures, the sensitivity, the specificity, and the positive and negative predictive values of the Xpert MRSA assay were $69.2 \%, 97.7 \%, 78.3 \%$, and $96.3 \%$ respectively. The 7 evaluable false-negative results according to the assay were due to its possible lack of sensitivity $(n=3)$ and to the occurrence of a Belgian MRSA clone carrying a particular staphylococcal chromosomal cassette mec (SCCmec) type IV variant $(n=4)$ not targeted by the current Xpert MRSA assay. Because of the evolution of SCCmec in MRSA, new primers should be designed and further studies are warranted to ensure continuous monitoring of this assay.

\section{Introduction}

Methicillin-resistant Staphylococcus aureus (MRSA) is one of the major nosocomial pathogens responsible for a wide spectrum of infections and associated with high morbidity and mortality rates, particularly in geriatric patients [1-4]. In Belgium, studies carried out in nursing home residents suggest that the prevalence of MRSA carriage in older population has significantly increased over the last few years, rising from $4.7 \%$ in 2002 [4] up to $19 \%$ in 2005 [5]. In acute care hospitals, the current importation rate exceeds the nosocomial acquisition rate. In 2008, the report of the Belgian Scientific Institute of Public Health showed between January and June 2008 a nosocomial incidence of 2 patients/ 1,000 admissions, whereas the importation rate averaged 8.3 patients/1,000 admissions. Nursing homes were identified as a major reservoir of MRSA, since $16.1 \%$ of all patients colonized with MRSA upon hospital admission were elderly residents transferred from a long-term care facility (http:// www.iph.fgov.be/nsih/surv_mrsa/download_fr.asp). 
Highly efficient admission screening protocols and rapid implementation of additional precautions are essential to control the nosocomial spread of MRSA [6]. The current national guidelines for MRSA screening in Belgium recommend culture swabs from nares and other skin and mucosal sites using both enrichment broth and selective culture media (http://www.belgianinfectioncontrolsociety.be). Although the use of chromogenic selective culture media has shortened the turnaround detection time the results are usually not available before $48 \mathrm{~h}$ [7]. Rapid MRSA detection using commercial or in-house PCR assays has been recently developed and is potentially relevant for patient management [8]. The Xpert MRSA kit (Cepheid; Sunnyvale, CA, USA) is a second-generation, real-time PCR assay targeting MRSA-specific DNA sequences at the chromosomal $\operatorname{orf} X$-staphylococcal chromosomal cassette mec ( $\mathrm{SCCmec}$ ) junction and it is approved for the screening of MRSA on nasal swab specimens using the GeneXpert real-time PCR platform.

The aim of the present study was to assess the performance of the Xpert MRSA assay for screening MRSA carriage in geriatric patients at admission and compare it with culture on selective chromogenic agar media (CAM) with prior broth enrichment. In addition, we challenged the ability of the Xpert kit to detect MRSA selected from a well-characterized collection representative of MRSA recovered in Belgium between 2002 and 2007.

\section{Materials and methods}

MRSA strain collection

A collection of 40 MRSA strains representative of MRSA isolates recovered in Belgium between 2002 and 2007 were analyzed to assess the ability of the Xpert MRSA kit to detect the major Belgian epidemic MRSA clones. These MRSA strains were collected from national MRSA surveys and from the Reference Laboratory collection and characterized by pulsed field gel electrophoresis (PFGE), spa typing and multilocus sequence typing (MLST) as previously described [9]. SCCmec types of strains were determined by methods described by Oliveira and de Lancestre [10], Zhang et al. [11] and Kondo et al. [12]. The collection included three sets of distinct MRSA strains. The first included 30 healthcare-associated (HA) MRSA isolates collected during the national survey conducted in 2003. The second set included 7 Panton-Valentine leucocidin (PVL)-positive community-acquired (CA) MRSA strains collected in Belgium between 2002 and 2005. The last set included three MRSA strains recovered from pigs in Belgium in 2007 (Table 1).

Isolates were prepared in saline suspensions at a concentration of $10^{6} \mathrm{CFU} / \mathrm{ml}(100 \mu \mathrm{l}$ of a $0.5 \mathrm{McF}$ arland suspension diluted in $10 \mathrm{ml}$ of physiological saline solution) and absorbed onto double Copan swabs. One swab was tested with the Xpert MRSA assay and the other swab was cultured onto CAM and in TSB enrichment broth. Any isolate negative according to the Xpert MRSA kit was retested a second time on the GeneXpert system with an Xpert MRSA cartridge and was also tested with an Xpert SA SSTI cartridge able to detect independently $m e c \mathrm{~A}, s p a$, and the $\mathrm{SCCmec}$ cassette.

Patients and clinical samples

The study was conducted prospectively in a 32-bed geriatric ward of a 390-bed tertiary-care hospital (MontGodinne University Hospital, Yvoir, Belgium). Geriatric ward staff were given the instructions to include in the study all patients admitted to the geriatric ward between November 2007 and July 2008 and who
Table 1 Representative methicillin-resistant Staphylococcus aureus (MRSA) isolates $(n=40)$ from a collection recovered in Belgium 2002-2007
PFGE, pulsed field gel electrophoresis; NT, not typable by PFGE analysis; MLST, multilocus sequence typing; SCC mec, staphylococcal chromosomal cassette mec

\begin{tabular}{|c|c|c|c|c|}
\hline Origin & PFGE type (number of isolates) & $\operatorname{MLST}(\mathrm{ST})$ & SCCmec type & Isolation year \\
\hline \multirow[t]{7}{*}{ HA-MRSA } & A20 (5) & ST8 & IV & 2003 \\
\hline & A1 (2) & ST247 & I & 2003 \\
\hline & B2 (5) & ST45 & IV & 2003 \\
\hline & G10 (5) & ST5 & II & 2003 \\
\hline & L1 (4) & ST22 & IV & 2003 \\
\hline & D8 (4) & ST228 & I & 2003 \\
\hline & $\mathrm{C} 2, \mathrm{C} 3(5)$ & ST5 & IV & 2003 \\
\hline \multirow[t]{4}{*}{ CA-MRSA } & $\mathrm{J} 4(2)$ & ST30 & IV & $2002-2005$ \\
\hline & $\mathrm{A} 23, \mathrm{~A} 24(2)$ & ST8 & IV & $2002-2005$ \\
\hline & Sporadic (1) & & IV & $2002-2005$ \\
\hline & Sporadic (2) & & $\mathrm{V}$ & $2002-2005$ \\
\hline \multirow[t]{2}{*}{ Pig MRSA } & NT (1) & ST398 & IV & 2007 \\
\hline & NT (2) & ST398 & $\mathrm{V}$ & 2007 \\
\hline
\end{tabular}


presented at least one risk factor for MRSA carriage (i.e., antimicrobial therapy within the last 3 months, transfer from another hospital or from a nursing home, hospitalization in the previous year, presence of chronic wounds, past history of MRSA carriage or infection). Since the primary goal of this study was to evaluate the technical performance of the Xpert MRSA assay without any specific clinical endpoint, all nasal specimens sent to the laboratory including those collected from patients without risk factors were run on GeneXpert. Each subject was enrolled in the study only once per admission. Subjects who had received systemic or topical antibiotics active against MRSA isolates during a period up to 1 week prior to enrolment were excluded from the study. The study protocol was approved by the ethics committee of our institution.

\section{Selective cultures and Xpert MRSA assays}

Methicillin-resistant Staphylococcus aureus screening was performed as recommended by the Belgian Infection Control Society (BICS) by swabbing nares, throat, axilla, perineum, and any skin wound (when present). Nasal swabs were collected using a double swab (Copan 139 C; Copan Italia SPA, Brescia, Italy). The first swab was tested using the Xpert MRSA assay on a GeneXpert DX system, version 1.2 (Cepheid) according to the manufacturer's instructions. The second swab was inoculated on a chromogenic agar (CAM) MRSA Select (Bio-Rad, Marne La Coquette, France) and subsequently cultured into tryptic soy broth (TSB) (BD211825; Becton Dickinson) supplemented with $6.5 \% \mathrm{NaCl}$. Extra-nasal samples were collected with single Copan swabs, pooled together in sterile water and processed by the same routine culture techniques as were used for nasal swabs. Since the Xpert MRSA kit was only approved for nasal swabs, extra-nasal specimens were not run with this assay. The CAM and the enrichment broth were incubated for $24 \mathrm{~h}$ at $35^{\circ} \mathrm{C}$. For negative primary culture on CAM, TSB $(10 \mu \mathrm{l})$ was subcultured onto CAM and was further incubated for $24 \mathrm{~h}$ at $35^{\circ} \mathrm{C}$.

Specimens for Xpert MRSA assay and for culture were processed 6 days a week (Monday to Saturday from 8 a.m. to 7 p.m.). The Xpert MRSA assays were processed upon arrival of the specimens to the laboratory (whenever possible) while all cultures were processed in batches once a day (at noon). All specimens were stored at $+4^{\circ} \mathrm{C}$ until testing.

\section{MRSA identification}

Growth was confirmed as MRSA using VITEK 2 identification and antimicrobial susceptibility testing galleries (GPID and AST-P549 cards; bioMérieux, Craponne, France) and the presence of mecA was further confirmed by a conventional in-house PCR assay [7]. All MRSA isolates were preserved at $-70^{\circ} \mathrm{C}$ on cryoprotective beads.

The MRSA isolates recovered from specimens yielding culture-positive results and kit-negative results were prepared in suspensions in saline solution at concentrations of $10^{6} \mathrm{CFU} / \mathrm{ml}$, adsorbed on Copan swabs and retested using the Xpert MRSA kit. The strains not recognised as MRSA by Xpert MRSA were also tested with an Xpert SA SSTI cartridge able to detect independently mecA, spa, and the $\mathrm{SCCmec}$ cassette.

\section{Molecular typing}

All MRSA isolates were characterized using PFGE analysis (SmaI) and spa typing, as previously described [9]. SCCmec types were determined by multiplex PCR [10, 11]. MRSA isolates that were SCCmec non-typable by multiplex PCR had their $c c r$ type and mec class determined by the PCR described by Kondo et al. [12]. Five types of $c c r$ (1 to 5) and three classes of mec (A to C) were reported and SCCmec type was defined by a combination of $c \mathrm{cr}$ and mec complexes [12].

\section{Calculation of turnaround time}

We calculated the median total turnaround time on a sample of 150 nasal specimens. For Xpert MRSA results available before 7 p.m., we estimated the time elapsed between the sample arriving and the PCR result being encoded in our computer system and thus, when it would be available for geriatric staff. Xpert MRSA results obtained after 7 p.m. were arbitrarily considered as available at $8.30 \mathrm{a} . \mathrm{m}$. on the next working day. Since culture for MRSA specimens are processed in batches everyday at noon, results for specimens arriving before 12 a.m. were considered to be available on the next day at 12 a.m. Results for each specimen arriving after $12 \mathrm{a}$.m. were considered to be available at 12 a.m. on the second day after arriving in the laboratory. For specimens that yielded isolation of MRSA isolates only following enrichment culture, 24 additional hours were taken into account.

\section{Data analysis}

In the clinical trial, sensitivities, specificities, and positive and negative predictive values of the Xpert MRSA results were calculated according to a standard formula for nasal specimens only and compared with those obtained both with direct and enrichment cultures as the gold standard. True-positive and true-negative results were defined as giving identical results by culture and PCR. For patients with positive PCR, but negative culture, medical charts of patients were reviewed and Xpert MRSA were considered to be possibly true-positive 
if the patients had been previously positive for MRSA within the last 12 months or were culture-positive at another site.

\section{Results}

MRSA strain collection

The Xpert MRSA assay detected all but two MRSA strains belonging to epidemic genotypes frequently recovered in Belgian hospitals, community and animals. One of the strains (A20-ST8-SCCmec type IV) yielded a positive result upon retesting with the Xpert MRSA cartridge. The other bacterial isolate (A1-ST247-SCCmec type I) still remained undetected as MRSA following retesting; the $\mathrm{SCCmec}$ cassette of this strain was not recognized by the Xpert SA SSTI cartridge.

\section{Clinical study}

Out of 394 patients admitted to the geriatric department over an 8-month period (between October 2007 and August 2008), the geriatric staff sampled 246 patients for MRSA carriage by culture and PCR (192 with risk factor[s] for MRSA carriage and 54 without risk factor[s] for MRSA carriage). Five samples (2\%) were excluded from the study analysis because of invalid PCR results.

Methicillin-resistant Staphylococcus aureus was recovered by culture in specimens from 32 patients $(13.0 \%)$ including 30 with at least one risk factor. Among the 32 culture-positive specimens, MRSA were recovered from nasal swab specimens $(n=25)$ and from extra-nasal sites $(n=7)$.

Of the 25 MRSA-positive nasal swab specimens, 22 were detected by primary culture plating on selective chromogenic agar and 3 were detected by enrichment culture only. Twenty-three nasal specimens tested positive according to the Xpert MRSA assay, including 17 that were also positive according to culture (Table 2). One of six patients positive according to nasal sample tested by PCR, but negative according to culture had MRSA isolated from a wound culture specimen and was hence considered as a true-positive (Table 2). On the other hand, 8 out of 25 specimens $(32.0 \%)$ yielding MRSA by culture showed false-negative Xpert MRSA results. The sensitivity, specificity, and positive and negative predictive values of the Xpert MRSA assay were $78.3 \%, 97.7 \%, 78.3 \%$, and $97.7 \%$ respectively compared with direct culture, while they reached $69.2 \%, 97.7 \%, 78.3 \%$, and $96.3 \%$ respectively compared with enriched culture.

Seven out of the 8 culture-positive PCR-negative MRSA strains were available for retesting by GeneXpert directly from single colonies. Three of these were correctly assigned as MRSA, suggesting troubleshooting during the initial
Table 2 Results obtained with the Xpert MRSA assay and culture from 246 nasal samples (one per patient)

\begin{tabular}{|c|c|c|c|c|}
\hline & \multicolumn{4}{|c|}{ Xpert MRSA } \\
\hline & Positive & Negative & Invalid $^{\mathrm{e}}$ & Total \\
\hline Direct culture-positive $^{\mathrm{a}}$ & 17 & 5 & 0 & 22 \\
\hline $\begin{array}{l}\text { Enrichment culture- } \\
\text { positive }^{\mathrm{b}}\end{array}$ & 0 & 3 & 0 & 3 \\
\hline Total culture-positive & 17 & 8 & 0 & 25 \\
\hline Culture-negative $^{\mathrm{c}}$ & $6^{\mathrm{d}}$ & 210 & 5 & 221 \\
\hline
\end{tabular}

${ }^{\mathrm{a}}$ Includes the number of specimens that were positive according to direct culture on MRSA Select

${ }^{\mathrm{b}}$ Includes the number of specimens that were positive only after enrichment into $4 \mathrm{ml}$ tryptic soy broth $(6.5 \% \mathrm{NaCl})$

${ }^{\mathrm{c}}$ Includes number of specimens that were negative according to direct and enrichment culture

${ }^{\mathrm{d}}$ One of the 6 Xpert MRSA-positive/culture-negative specimens was considered to be a true-positive in the calculation of sensitivities, specificities, and positive and negative predictive values because of the simultaneous presence of MRSA at another site (wound specimen)

${ }^{\mathrm{e}}$ Invalid results according to Xpert MRSA assay

detection by Xpert MRSA assay (poor quality swabbing or lack of sensitivity) while 4 of the MRSA isolates remained undetected by the Xpert MRSA assay. Testing of these strains with the Xpert SA SSTI kit showed that, whereas mecA could be detected, the SCCmec cassette was not revealed by the system.

Among the 7 extra-nasal swab specimens, 5 were detected by primary culture and 2 were detected by enrichment culture only. As expected, the Xpert MRSA assay yielded negative results on all nasal samples of the 7 patients found to be colonized by MRSA at the culture of extra-nasal sites only. Extra-nasal specimens were not challenged on the GeneXpert system with the Xpert MRSA kit or with another cartridge.

\section{Molecular typing}

Only 24 out of 25 isolates recovered from positive cultures of nasal swabs were available for additional characterization. Molecular typing using PFGE analysis revealed six PFGE types A20, A21, A22, B2, C1, and C3 (Table 3). The majority of these MRSA clone types had been found to be predominant in previous Belgian national surveys. Analysis by spa typing confirmed PFGE classification showing identical or related spa types presenting up to two genetic mutational events (Table 3). Using Oliveira's and Zhang's PCR typing methods, SCCmec types II and IV were recovered in $3(13 \%)$ and $17(71 \%)$ MRSA isolates respectively. Intriguingly, the 4 MRSA isolates that could not be recognized as such by the Xpert MRSA assay were 
Table 3 Molecular analysis of MRSA nasal strains $\left(n=24^{\mathrm{a}}\right)$

\begin{tabular}{|c|c|c|c|c|c|}
\hline Number of isolates & $\begin{array}{l}\text { Xpert MRSA assay result } \\
\text { (pure culture result }{ }^{\mathrm{b}} \text { ) }\end{array}$ & PFGE type & spa type & spa profile & $\begin{array}{l}\text { SCCmec } \\
\text { type }^{\mathrm{d}}\end{array}$ \\
\hline 2 & Positive & $\mathrm{A} 20$ & t068 & $11-19-19-12-21-17-34-24-34-22-25$ & IV \\
\hline 4 & Positive & $\mathrm{A} 20$ & t008 & $11-19-12-21-17-34-24-34-22-25$ & IV \\
\hline 4 & Negative (Negative) & $A 20$ & t008 & $11-19-12-21-17-34-24-34-22-25$ & $N T$ \\
\hline 2 & Positive & A 21 & t008 & $11-19-12-21-17-34-24-34-22-25$ & IV \\
\hline 1 & Positive & A22 & t024 & $11-12-21-17-34-24-34-22-25$ & IV \\
\hline 1 & Positive & A22 & t068 & $11-19-19-12-21-17-34-24-34-22-25$ & IV \\
\hline 1 & Positive & A22 & t008 & $11-19-12-21-17-34-24-34-22-25$ & IV \\
\hline 1 & Positive & A22 & $\mathrm{t} 121$ & $11-19-21-17-34-24-34-22-25$ & IV \\
\hline 1 & Positive & $\mathrm{B} 2$ & $\mathrm{t} 1011$ & $08-39-34$ & IV \\
\hline 1 & Positive & $\mathrm{B} 2$ & t598 & $08-39-34-13-13-17-34-16-34$ & IV \\
\hline 1 & Negative (Positive) & $\mathrm{B} 2$ & $\mathrm{t} 4287$ & $08-39-34-34-13-17-34-34-16-13$ & IV \\
\hline 1 & Negative (Positive) & B2 & t655 & $08-39-34-34-17-34-16-34$ & IV \\
\hline 1 & Invalid $^{c}$ & B2 & t598 & $08-39-34-13-13-17-34-16-34$ & IV \\
\hline 1 & Positive & $\mathrm{C} 1$ & t003 & $26-17-20-17-12-17-17-16$ & II \\
\hline 1 & Positive & $\mathrm{C} 3$ & t003 & $26-17-20-17-12-17-17-16$ & II \\
\hline 1 & Negative (positive) & $\mathrm{C} 3$ & $\mathrm{t} 151$ & $26-17-20-17-16$ & II \\
\hline
\end{tabular}

Isolates showing discordant results between culture and Xpert MRSA assay are indicated in italics

${ }^{a}$ Only 24 of the 25 isolates recovered from positive cultures of nasal swabs were available for molecular characterization

${ }^{\mathrm{b}}$ For samples testing negative with the Xpert MRSA assay, the result of retesting of the isolate in pure culture in saline suspension at a concentration of $10^{6}$ $\mathrm{CFU} / \mathrm{ml}$ with the Xpert MRSA assay

${ }^{\mathrm{c}}$ Invalid results according to the Xpert MRSA assay

${ }^{\mathrm{d}}$ As determined according to Oliveira's and/or Zhang's methods

found to be untypeable by both methods, suggesting the possible occurrence of a particular cassette in those strains (Table 3). Determination of $\mathrm{ccr}$ and $\mathrm{mec}$ gene complexes in these isolates revealed mec class B and the presence of $\mathrm{ccr}$ of type 2 ( $c c r A 2 B 2)$ and of type 5 ( $c r C$; data not shown). These findings suggested a recombined SCCmec type IV, containing mec class B and $c c r$ complex 2 as defined, but combined to a fragment of the $c c r$ complex 5 described in SCCmec type V or in SCCmec type VII $[13,14]$.

Evaluation of turnaround time

The median turnaround time from receipt of the samples to availability of the results for the clinicians was $1.9 \mathrm{~h}(\mathrm{P} 25=$ 1.4; P75=4.2) with Xpert MRSA versus $42.6 \mathrm{~h}(\mathrm{P} 25=26.7$; $\mathrm{P} 75=44.3)$ for positive primary culture $(n=14)$ and $66.9 \mathrm{~h}$ $(\mathrm{P} 25=50.9 ; \mathrm{P} 75=67.9)$ for definitive culture results $(n=136)$.

\section{Discussion}

Methicillin-resistant Staphylococcus aureus constitutes a worrisome problem among geriatric patients who often present risk factors for its acquisition [5, 15]. Improvement of screening strategies to diagnose MRSA carriers upon admission and implementation of additional precautions are crucial to limiting the nosocomial transmission of this pathogen during hospitalization [6].

Recently, the introduction of selective chromogenic agar $[7,8]$ has improved the detection rate of MRSA and has reduced the detection time in screening samples. It has also been shown that PCR-based detection systems could further decrease the turnaround time of MRSA detection to a few hours [8].

The Xpert MRSA is a fully automated, friendly to use, real-time PCR assay allowing rapid detection of MRSA carriage. In this study, the Xpert MRSA detected all but one of the 40 MRSA challenged strains, but it identified only 17 of the $32(53 \%)$ MRSA carriers. Specimens from 8 patients with culture-positive nasal samples were missed by the PCR assay and 7 MRSA carriers who were only positive in extra-nasal sites could not be identified since the Xpert MRSA assay was only approved for nasal samples. The relatively low sensitivity (69.2\%) of the Xpert MRSA assay could limit the routine utility of the system. However, other evaluations of nasal screening using the Xpert MRSA assay reported higher sensitivities, e.g., $95 \%$ by Rossney et al. in Ireland [16], $86 \%$ by Wolk et al. in the United States for both patients and health care workers [17], and $87 \%$ by Kelley et al. in Australia [18]. 
Among the 8 MRSA isolates recovered by culture and not detected by the Xpert MRSA assay, 7 were available for retesting and further characterization. Three isolates were recognized as MRSA by a second PCR assay performed directly on single colony suspensions, suggesting a lack of sensitivity of the test (presence of MRSA at a low inoculum level or poor quality swabbing for the PCR swab). Similar false-negative results have previously been described [16, 19]. Rossney et al. found 18/19 culture-positive/PCRnegative MRSA strains that were recognized as MRSA by PCR assay performed on colony suspensions [16]. Recently, te Witt et al. also showed in an external quality assessment of molecular diagnostic testing that several commercial real-time PCR assays for MRSA detection yielded a sensitivity below $50 \%$ when a culture inoculum of as low as $10^{2} \mathrm{CFU} / \mathrm{ml}$ was tested [20]. In this study, four other MRSA isolates remained negative after retesting on pure culture suspensions. All four isolates had similar PFGE (A20) and spa type profiles (t008), but had a nontypable SCCmec according to both Oliveira's and Zhang's techniques. This MRSA clone corresponds to the A20-ST8-SCCmec IV clone that has been previously reported in Belgium [21] as well as in France [22]. Isolates belonging to this specific MRSA clone apparently carried a variant of SCCmec type IV, which carries a combination of two $c c r$ gene complexes ( $c c r A 2 B 2$ and $c c r C$ ). Additional analysis, including complete sequence determination of the SCCmec element, should be performed in order to understand why the current Xpert MRSA assay was unable to detect this variant. Inclusion of new primers/probe sets in an updated version of Xpert MRSA could increase the sensitivity of the GeneXpert System. Interestingly, Bartels et al. also reported a common type IVa variant of SCCmec in Denmark that could not be detected with the BD GeneOhm MRSA assay until new primers designed by the manufacturer were used [23].

One limitation of this study is that only local Belgian MRSA strains were run on the Xpert MRSA assay. While it appears that the performance of the Xpert MRSA assay would probably have been significantly increased without the presence of the A20-ST8-SCCmec IV clone, the comparison with results from other publications remains difficult for several reasons. As a matter of fact, the prevalence of MRSA isolates carrying variants of SCCmec cassettes is usually unknown or not analyzed in most studies. Further, molecular typing of the MRSA strains or PCR retesting from colony suspensions of culture-positive/PCR-negative MRSA strains are often not performed, except in the study by Rossney et al. [16]. Our data reemphasize the need to evaluate the performance of commercial PCR assays on local strains and also stress the importance of regular updates by the manufacturers of molecular assays to follow the genetic evolution of nosocomial pathogens [24].
The relatively low positive predictive value $(78.3 \%)$ found in our study was similar or inferior to those reported by Wolk et al. (81\%) [17] and by Rossney et al. (90\%) [16] . False-positive results could theoretically be explained by the presence of amplifiable DNA originating from nonviable strains of treated patients [25]. However, we could not find any evidence of the recent use of topical or systemic antibiotics active against MRSA strains that might have accounted for the PCR-positive/culture-negative results in our patients. Another hypothesis for PCR-positive/culturenegative results might be a lower sensitivity of culture. Rossney et al. [16] recently demonstrated that the Xpert MRSA assay has a higher limit of detection $(58 \mathrm{CFU} / \mathrm{ml})$ than optimized culture using both enrichment broth and selective chromogenic agar (9 CFU/ml) [16]. A similar limit of detection of the Xpert MRSA assay (around $80 \mathrm{CFU} / \mathrm{ml}$ ) was further confirmed by Wolk et al. [17]. Moreover, Rossney et al. showed the possibility of false-positive results by the Xpert MRSA assay for mixed culture cocktails of MSSA in the absence of MRSA [16], although no explanation of this misclassification was provided.

The possible occurrence of methicillin-susceptible $S$. aureus (MSSA) strains containing an SCC element lacking the mecA gene could also have accounted for some of the false-positive results observed with different diagnostic molecular assays of MRSA [19, 20, 26, 27]. The real prevalence of such variants is unknown, but could vary geographically and it should be closely monitored when commercial PCR assays are used for screening [24]. In our study the possibility of such an occurrence would have been impossible to demonstrate, since we did not use nonselective culture media that could have made possible the recovery of MSSA strains.

Besides these technical considerations, it should also be emphasized that few studies have been able to demonstrate that rapid MRSA detection by PCR has a clinical impact in comparison to culture-based methods [28, 29]. Several reports have shown reduced rates of surgical site infections and of nosocomial transmission when a real-time PCR assay was used [30-32]. On the other hand, in a recent meta-analysis, Tacconelli et al. failed to observe a decrease in the nosocomial acquisition rate of MRSA with the use of rapid molecular screening tests compared with culture [33]. Several studies clearly demonstrated a shortened turnaround time with the use of real-time PCR methods [29, 30, 34, 35], while a possible benefit in reducing the costs generated by the reduction of preemptive patient isolation could usually not be demonstrated $[35,36]$. Further, most studies were performed in populations with a low prevalence of MRSA; these results should therefore be confirmed by further evaluations in populations with higher MRSA prevalence.

In conclusion, the Xpert MRSA assay is a fully automated and user-friendly real-time PCR assay allowing reduction in turnaround time for $53 \%$ of the MRSA carriers 
in our geriatric unit, but the impact on MRSA transmission could not be evaluated because of the small number of patients included. However, we observed a substantial number of false-positive and false-negative results with the Xpert MRSA assay, possibly due to a lack of sensitivity or to the emergence in Belgian hospitals of MRSA strains containing a SCCmec type IV variant. The possibility of misclassification of MRSA as well as the high cost of PCR in comparison to culture underlines the need for more in-depth local evaluations before implementing this technology for routine MRSA screening on admission.

Acknowledgements We thank the participating patients, the infection control and nursing staff (Serge Dupont, Laurent Tonnoir) and the clinical staff of the geriatric unit at UCL Mont-Godinne hospital for providing duplicate specimens. We thank Mrs. Kathleen Stam and Mr. Luc De Bock, Lucron Belgium, and Cepheid for providing the GeneXpert machine for the duration of the evaluation and for providing the Xpert MRSA kits at an evaluation price.

Conflicts of interest None.

\section{References}

1. Malani PN, Rana MM, Banerjee M, Bradley SF (2008) Staphylococcus aureus bloodstream infections: the association between age and mortality and functional status. J Am Geriatr Soc 56(8):1485-1489

2. Shurland S, Zhan M, Bradham DD, Roghmann MC (2007) Comparison of mortality risk associated with bacteremia due to methicillin-resistant and methicillin-susceptible Staphylococcus aureus. Infect Control Hosp Epidemiol 28(3):273-279

3. Tacconelli E, Pop-Vicas AE, D'Agata EM (2006) Increased mortality among elderly patients with meticillin-resistant Staphylococcus aureus bacteraemia. J Hosp Infect 64(3):251-256

4. Suetens C, Niclaes L, Jans B, Verhaegen J, Schuermans A, Van Eldere J, Vandenbroucke JP, Buntinx F (2007) Determinants of methicillin-resistant Staphylococcus aureus carriage in nursing homes. Age Ageing 36(3):327-330

5. Jans B, Suetens C, Denis O, Struelens MJ (2006) The first national methicillin resistant Staphylococcus aureus prevalence study in Belgian nursing homes indicates high carriage rate among residents. In: Abstracts of the 16th European Congress of Clinical Microbiology and Infectious Diseases (Nice). Abstract no. P-0316

6. Calfee DP, Salgado CD, Classen D, Arias KM, Podgorny K, Anderson DJ, Burstin H, Coffin SE, Dubberke ER, Fraser V, Gerding DN, Griffin FA, Gross P, Kaye KS, Klompas M, Lo E, Marschall J, Mermel LA, Nicolle L, Pegues DA, Perl TM, Saint S, Weinstein RA, Wise R, Yokoe DS (2008) Strategies to prevent transmission of methicillin-resistant Staphylococcus aureus in acute care hospitals. Infect Control Hosp Epidemiol 29 [Suppl 1]: S62-S80

7. Lee S, Park YJ, Yoo JH, Kahng J, Jeong IH, Kwon YM, Han K (2008) Comparison of culture screening protocols for methicillinresistant Staphylococcus aureus (MRSA) using a chromogenic agar (MRSA-Select). Ann Clin Lab Sci 38(3):254-257

8. Malhotra-Kumar S, Haccuria K, Michiels M, Ieven M, Poyart C, Hryniewicz W, Goossens H (2008) Current trends in rapid diagnostics for methicillin-resistant Staphylococcus aureus and glycopeptide-resistant enterococcus species. J Clin Microbiol 46 (5):1577-1587
9. Hallin M, Denis O, Deplano A, De Mendonca R, De Ryck R, Rottiers S, Struelens MJ (2007) Genetic relatedness between methicillin-susceptible and methicillin-resistant Staphylococcus aureus: results of a national survey. J Antimicrob Chemother 59 (3):465-472

10. Oliveira DC, de Lencastre H (2002) Multiplex PCR strategy for rapid identification of structural types and variants of the mec element in methicillin-resistant Staphylococcus aureus. Antimicrob Agents Chemother 46(7):2155-2161

11. Zhang K, McClure JA, Elsayed S, Louie T, Conly JM (2005) Novel multiplex PCR assay for characterization and concomitant subtyping of staphylococcal cassette chromosome mec types I to $\mathrm{V}$ in methicillin-resistant Staphylococcus aureus. J Clin Microbiol 43(10):5026-5033

12. Kondo Y, Ito T, Ma XX, Watanabe S, Kreiswirth BN, Etienne J, Hiramatsu K (2007) Combination of multiplex PCRs for staphylococcal cassette chromosome mec type assignment: rapid identification system for mec, ccr, and major differences in junkyard regions. Antimicrob Agents Chemother 51(1):264-274

13. International Working Group on the Classification of Staphylococcal Cassette Chromosome Elements (IWG-SCC) (2009) Classification of staphylococcal cassette chromosome mec (SCCmec): guidelines for reporting novel SCCmec elements. Antimicrob Agents Chemother 53(12):4961-4967

14. Berglund C, Ito T, Ikeda M, Ma XX, Soderquist B, Hiramatsu K (2008) Novel type of staphylococcal cassette chromosome mec in a methicillin-resistant Staphylococcus aureus strain isolated in Sweden. Antimicrob Agents Chemother 52(10):3512-3516

15. Sax H, Harbarth S, Gavazzi G, Henry N, Schrenzel J, Rohner P, Michel JP, Pittet D (2005) Prevalence and prediction of previously unknown MRSA carriage on admission to a geriatric hospital. Age Ageing 34(5):456-462

16. Rossney AS, Herra CM, Brennan GI, Morgan PM, O'Connell B (2008) Evaluation of the Xpert methicillin-resistant Staphylococcus aureus (MRSA) assay using the GeneXpert real-time PCR platform for rapid detection of MRSA from screening specimens. J Clin Microbiol 46(10):3285-3290

17. Wolk DM, Picton E, Johnson D, Davis T, Pancholi P, Ginocchio CC, Finegold S, Welch DF, de Boer M, Fuller D, Solomon MC, Rogers B, Mehta MS, Peterson LR (2009) Multicenter evaluation of the Cepheid Xpert methicillin-resistant Staphylococcus aureus (MRSA) test as a rapid screening method for detection of MRSA in nares. J Clin Microbiol 47(3):758-764

18. Kelley PG, Grabsch EA, Howden BP, Gao W, Grayson ML (2009) Comparison of the Xpert methicillin-resistant Staphylococcus aureus (MRSA) assay, BD GeneOhm MRSA assay, and culture for detection of nasal and cutaneous groin colonization by MRSA. J Clin Microbiol 47(11):3769-3772

19. Farley JE, Stamper PD, Ross T, Cai M, Speser S, Carroll KC (2008) Comparison of the BD GeneOhm methicillin-resistant Staphylococcus aureus (MRSA) PCR assay to culture by use of BBL CHROMagar MRSA for detection of MRSA in nasal surveillance cultures from an at-risk community population. J Clin Microbiol 46(2):743-746

20. Te Witt R, van Belkum A, MacKay WG, Wallace PS, van Leeuwen WB (2010) External quality assessment of the molecular diagnostics and genotyping of meticillin-resistant Staphylococcus aureus. Eur J Clin Microbiol Infect Dis 29(3):295-300

21. Denis O, Jans B, Deplano A, Nonhoff C, De Ryck R, Suetens C, Struelens MJ (2009) Epidemiology of methicillinresistant Staphylococcus aureus (MRSA) among residents of nursing homes in Belgium. J Antimicrob Chemother 64 (6):1299-1306

22. Dauwalder O, Lina G, Durand G, Bes M, Meugnier H, Jarlier V, Coignard B, Vandenesch F, Etienne J, Laurent F (2008) Epidemiology of invasive methicillin-resistant Staphylococcus 
aureus clones collected in France in 2006 and 2007. J Clin Microbiol 46(10):3454-3458

23. Bartels MD, Boye K, Rohde SM, Larsen AR, Torfs H, Bouchy P, Skov R, Westh H (2009) A common variant of staphylococcal cassette chromosome mec type IVa in isolates from Copenhagen, Denmark, is not detected by the BD GeneOhm methicillinresistant Staphylococcus aureus assay. J Clin Microbiol 47 (5): 1524-1527

24. Francois P, Bento M, Renzi G, Harbarth S, Pittet D, Schrenzel J (2007) Evaluation of three molecular assays for rapid identification of methicillin-resistant Staphylococcus aureus. J Clin Microbiol 45(6):2011-2013

25. De San N, Denis O, Gasasira MF, De Mendonca R, Nonhoff C, Struelens MJ (2007) Controlled evaluation of the IDI-MRSA assay for detection of colonization by methicillin-resistant Staphylococcus aureus in diverse mucocutaneous specimens. J Clin Microbiol 45(4):1098-1101

26. Rupp J, Fenner I, Solbach W, Gieffers J (2006) Be aware of the possibility of false-positive results in single-locus PCR assays for methicillin-resistant Staphylococcus aureus. J Clin Microbiol 44 (6): 2317

27. Shore AC, Rossney AS, O'Connell B, Herra CM, Sullivan DJ, Humphreys H, Coleman DC (2008) Detection of staphylococcal cassette chromosome mec-associated DNA segments in multiresistant methicillin-susceptible Staphylococcus aureus (MSSA) and identification of Staphylococcus epidermidis ccrAB4 in both methicillin-resistant S. aureus and MSSA. Antimicrob Agents Chemother 52(12):4407-4419

28. Harbarth S, Masuet-Aumatell C, Schrenzel J, Francois P, Akakpo C, Renzi G, Pugin J, Ricou B, Pittet D (2006) Evaluation of rapid screening and pre-emptive contact isolation for detecting and controlling methicillin-resistant Staphylococcus aureus in critical care: an interventional cohort study. Crit Care 10(1):R25

29. Jeyaratnam D, Whitty CJ, Phillips K, Liu D, Orezzi C, Ajoku U, French GL (2008) Impact of rapid screening tests on acquisition of meticillin resistant Staphylococcus aureus: cluster randomised crossover trial. BMJ 336(7650):927-930

30. Cunningham R, Jenks P, Northwood J, Wallis M, Ferguson S, Hunt S (2007) Effect on MRSA transmission of rapid PCR testing of patients admitted to critical care. J Hosp Infect 65 (1):24-28

31. Jog S, Cunningham R, Cooper S, Wallis M, Marchbank A, VascoKnight P, Jenks PJ (2008) Impact of preoperative screening for meticillin-resistant Staphylococcus aureus by real-time polymerase chain reaction in patients undergoing cardiac surgery. J Hosp Infect 69(2):124-130

32. Keshtgar MR, Khalili A, Coen PG, Carder C, Macrae B, Jeanes A, Folan P, Baker D, Wren M, Wilson AP (2008) Impact of rapid molecular screening for meticillin-resistant Staphylococcus aureus in surgical wards. Br J Surg 95(3):381-386

33. Tacconelli E, De Angelis G, de Waure C, Cataldo MA, La Torre G, Cauda R (2009) Rapid screening tests for meticillin-resistant Staphylococcus aureus at hospital admission: systematic review and meta-analysis. Lancet Infect Dis 9(9):546-554

34. Andersen BM, Tollefsen T, Seljordslia B, Hochlin K, Syversen G, Jonassen TO, Rasch M, Sandvik L (2010) Rapid MRSA test in exposed persons: costs and savings in hospitals. J Infect 60 (4):293-299

35. Wassenberg MW, Kluytmans JA, Box AT, Bosboom RW, Buiting AG, van Elzakker EP, Melchers WJ, van Rijen MM, Thijsen SF, Troelstra A, Vandenbroucke-Grauls CM, Visser CE, Voss A, Wolffs PF, Wulf MW, van Zwet AA, de Wit GA, Bonten MJ (2010) Rapid screening of methicillin-resistant Staphylococcus aureus (MRSA) using PCR and chromogenic agar: a prospective study to evaluate costs and effects. Clin Microbiol Infect 10.1111/ j.1469-0691.2010.03210.x

36. Nulens E, Descheemaeker P, Deurenberg RH, Stobberingh EE, Gordts B (2010) Contribution of two molecular assays as compared to selective culture for MRSA screening in a low MRSA prevalence population. Infection 38(2):98-101 